\title{
An Integrative Knowledge Management Framework to Support ERP Implementation for Improved Management Decision Making in Industry
}

\author{
Uchitha Jayawickrama, Shaofeng Liu, and Melanie Hudson Smith \\ School of Management, University of Plymouth, Plymouth, United Kingdom \\ \{uchitha.jayawickrama, shaofeng.liu, \\ melanie.hudson-smith\}@plymouth.ac.uk
}

\begin{abstract}
Knowledge Management (KM) has been identified as one of the key success factors for Enterprise Resource Planning (ERP) implementation and has received considerable academic attention in the last decade, whilst continuously gaining interest from industry. KM for ERP implementation is, however, a challenging task because of the complexity of ERP packages used in various industrial contexts. If implemented successfully, ERP systems will improve management decision making by providing more accurate, timely and integrated enterprise wide information. This study proposes an integrative KM competence (IKMC) framework that can provide holistic consideration of different types of knowledge across its life cycle phases. The framework has been tested with companies in service industry which have implemented standard ERP packages. The key findings indicate how to advance KM competence by knowledge creation, transfer, retention and application. In addition, the study informs practitioners about the most important knowledge types (ERP package and business process knowledge) and how, why and with what to create, transfer, retain and re-use knowledge during an ERP implementation to achieve project success.
\end{abstract}

Keywords: knowledge management competence, enterprise resource planning, integrative framework, management decision making.

\section{Introduction}

The global business environment has changed dramatically in recent years, as competition in complex knowledge based economies has increased. Enterprise Resource Planning (ERP) systems have been viewed as a way to manage increased business complexity, leading to the rapid adoption and implementation of such systems, as ERP can support enterprises to improve decision making performance $[1,2]$. ERP is a strategic decision support tool that helps a company to gain competitive advantage by integrating business processes and optimising the resources available [3]. Over the past two decades, ERP systems have become one of the most important implementations in the corporate use of information technology. ERP implementations are usually large, complex projects, involving large groups of people and other resources, working collaboratively under considerable time pressure and facing many unforeseen developments $[4,5]$. 
More recently, knowledge management (KM) has emerged as a discrete area in the study of organisations, to the extent that it has become recognized as a significant source of competitive advantage [6]. Effectively implementing a sound KM strategy and becoming a knowledge-based company is seen as a mandatory condition of success for organizations as they enter the era of the knowledge economy [7]. ERP systems are expected to reduce costs by improving efficiencies through process advancements and enhance decision making by providing more accurate and timely enterprise wide integrated information [8]. The prospect of synergies between KM and ERP areas makes it an attractive area for current research, using KM to help face the challenge of increasing the success rate of ERP and reducing the risk of the implementation. Hence, this paper proposes an integrative KM competence framework for ERP success is reviewed in Section 2. Section 3 proposes an integrative KM competence framework and examines its main components. Thereafter and investigates the applicability of the framework in practice to guide future ERP implementations in industrial context towards success by increasing KM competence.

The rest of the paper is organised as follows: relevant literature on KM and ERP implementation, data collection approach together with data analysis and findings are presented in Section 4. Section 5 provides further discussion on the framework. Finally, management implications, limitations and further research are considered in the Conclusion section.

\section{Relevant Literature}

The majority of research in ERP system implementation is focused on critical success factors, critical failure factors, risk factors and effective factors relating to ERP implementations [9-15]. However, there are relatively few studies which specifically focus on knowledge management competence for ERP implementation success. This section mainly discusses the various KM and ERP implementation related literature.

Vandaie [16] identifies two major areas of concern regarding the management of knowledge in ERP projects through the developed framework; managing tacit knowledge and issues concerning the process-based nature of organizational knowledge. Furthermore, he identifies that facilitators are able to moderate these negative effects. The structure of team interactions and the atmosphere of the team help to moderate negative effects that are due to the tacit nature of ERP knowledge. Similarly, powerful core ERP teams and hiring in external consultants help to moderate the negative effects of the process-based nature of ERP knowledge and organisational memory. This study discusses two major barriers in knowledge creation and transfer in ERP projects and ways to mitigate them.

There is a large, significant and positive relationship between knowledge management competence and enterprise success, according to the quantitative study by Sedera and Gable [17]. The proposed model also demonstrates the equal importance of the four phases of the KM competence i.e. creation, transfer, retention and application. Furthermore, Sedera, Gable and Chan [18], Gable, Sedera and Chan [19] revealed that information quality, system quality, individual impact and organizational impact as variables in order to measure ERP success. The higher the 
organisation's level of enterprise system (ES) related KM competence; the higher the level of success of the ES will be [17]. Moreover, they explain almost half of the variance in ES success; thereby study identifies KM competence as possibly the most important antecedent of success.

Jones, Cline and Ryan [5] examined eight dimensions of culture and their impact on how the ERP implementation team is able to effectively share knowledge during implementation. This study shows ways to overcome cultural barriers to knowledge sharing. Furthermore, it develops a model that demonstrates the link between the dimensions of culture, and knowledge sharing during ERP implementation.

Maditinos, Chatzoudes and Tsairidis [20] introduce a conceptual framework that investigates the way that human inputs are linked to communication effectiveness, conflict resolution and knowledge transfer. They also show the effect of the above factors on successful ERP implementation. Moreover, they find that knowledge transfer is positively related to user support and consultant support. These findings are largely based on the phases of knowledge management i.e. creation, transfer, retention and application.

O'Leary [21] investigates the use of KM to support ERP systems across the entire life cycle, with particular interest in case-based KM. Organisation culture, business framework, ERP package and project are the knowledge types identified by Alavi and Leidner [22]. This is the only study which considered most knowledge types (four) in one study in order to understand the knowledge management for ERP domain broader. Chen [23] divides empirical knowledge into four different layers of "knowwhat", "know-why", "know-how", and "know-with" in the conceptual model based on the empirical knowledge characterization. Liu et al. [24] presented a waste elimination model which comprises of four knowledge layers (know-what, knowhow, know-why and know-with) and seven knowledge components (over production, waiting time, excessive processes, defectives, excessive inventory, excessive motion and excessive transport) in order to develop a knowledge-based decision making system to offer organisation-wide waste elimination guidance and recommendations in the electronics manufacturing industry.

The common feature of the past studies discussed in this section is that they explored knowledge types, knowledge layers and KM life cycle phases in isolation. None of the studies were able to explore the integrated effect of knowledge types, knowledge layers and KM life cycle phases for ERP implementation. Although effective KM has been identified as one of the key drivers for successful ERP implementations, there has been a significant shortage of empirical research on management of knowledge related to ERP implementation [25]. Understanding this, it is quite evident that KM competence for ERP success domain demands more research.

\section{An Integrative Knowledge Management Competence (IKMC) Framework}

An integrative framework has been proposed based on a comprehensive literature review on KM competence and ERP implementation and the research gap identified 
in this particular area. The integrative KM competence (IKMC) framework defines its key components (including k-types, k-layers and KM life cycle phases) and the relationships between the components, as shown in Figure 1.

A positive relationship between KM competence and ERP success (measured by information quality, system quality, individual impact and organizational impact) and the significant contribution towards KM competence by KM life cycle phases were incorporated to this framework. The four ERP implementation success measures can be elaborated as follows [17-19]. Individual impact is concerned with how ERP system has influenced user's individual capabilities and effectiveness on behalf of the organization. Organizational impact refers to impact of ERP system at the organizational level; namely improved organisational results and capabilities. Information quality is concerned with the quality of ERP system outputs: namely, the quality of the information the system produces in reports and on screen. System quality of the ERP system is concerned with how the system designs to capture data from a technical and design perspective. KM competence is defined for this study by considering literature as the effective management of relevant knowledge for successful implementation of the ERP system [17-19]. Moreover, KM competence investigates with the support of three main components; k-types, k-layers and KM life cycle (see Figure 1) which provide the integrative perspective for KM competence for ERP success. KM life cycle comprises of four phases according to many research studies [22, 26-32]. They are k-creation, k-transfer, k-retention and k-application. The ERP related knowledge is created with the interactions of project team members both client and vendor, then the created knowledge is transferred from one party to other, thereafter the transferred knowledge is retained with the use of various methods, finally retained knowledge is re-used when required during the implementation. The unique feature of this study is that it explores the integrated effect of k-types, k-layers and KM life cycle phases for ERP implementation success.

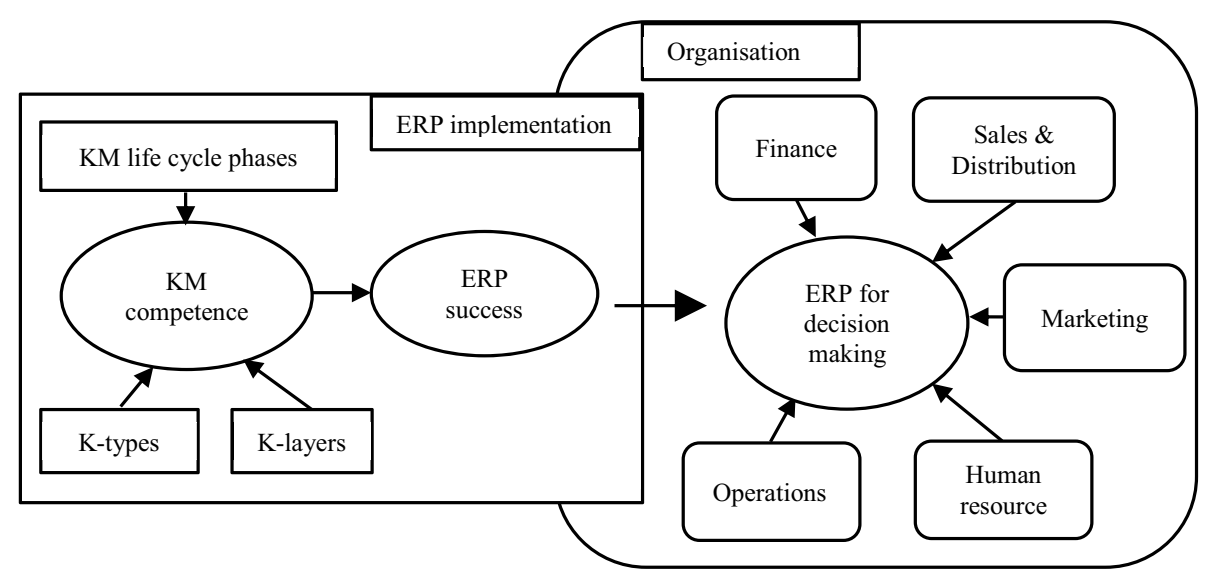

Fig. 1. Integrative KM Competence (IKMC) framework for ERP success 
The k-types component considers four types of knowledge: ERP package knowledge, business process knowledge, organisational knowledge and project management knowledge [5, 20, 22, 33]. ERP package related knowledge explains as knowledge pertaining to features and functions of the system, business process related knowledge refers to As Is or existing process knowledge, Organisational cultural related knowledge explains the attitudes and behavioural aspect of the employees of an organisation, project management related knowledge refers to use of methodologies and approaches to manage the ERP implementation. The k-layers are comprised of know-what, know-how, know-why and know-with [23, 34]. Incorporating the k-layers component in the IKMC framework enables to discover what, how, why and with-what (ERP package, business process, organisational cultural and project management) knowledge have been created, transferred, retained and applied during ERP implementations.

An ERP system can be considered as a basic transactional system, which can be used for processing business transactions and as a management control system, which facilitates the planning and communication of business targets and goals [35]. Sammon, Adam and Carton [36] describe these 2 components of ERP systems as the solution to "operational" integration problems and "informational" requirements of managers. Nah, Lau and Kuang [9] expressed the same concepts by describing the use of information systems not only to automate manual tasks, but also to informate management tasks. ERP systems act as a decision support system and facilitate to make integrated decisions in functional areas of an organisation such as finance, operations, sales and distribution, human resource, marketing and so on [1, 9, 11, 13] (see Figure 1). However, ERP systems should be implemented correctly by effectively managing knowledge during the implementation in order to satisfy business needs and improve decision making performance $[1,2]$. Hence, in the IKMC framework, ERP success measures have been used to achieve the enterprise wide decision making requirements of the organisation after the implementation.

The significance of the IKMC framework is that it provides an integrative perspective for KM competence through defining the relationships between its three main components i.e. k-types, k-layers and KM life cycle. For instance, it attempts to find out what sort of ERP package knowledge has been created during ERP implementation, how ERP package knowledge has been transferred during ERP implementation, etc. So, there would be various possible combinations of questions and answers that can be revealed through this integrative framework.

\section{Empirical Investigation with the Service Industry}

The previous section discusses the integrative framework proposed in this paper. The empirical investigation focuses on the data collection approach as well as data analysis and findings under two separate sub sections. 


\subsection{Data Collection Approach}

Insightful interview has been used as the main approach for data collection from industry. The face-to-face, in-depth interviews have been chosen over other data collection methods mainly because they provide the ability to gather rich and detailed responses for what, how, why and with what, the four types of knowledge have been created, transferred, retained and applied during ERP implementation [6, 37, 38]. There are criteria for selecting suitable interview participants from the companies as nature of the research demands [5, 39] and the developed criteria for this study are as follows; participant should have directly involved with the standard ERP system (SAP, Oracle, JD Edwards, MS Dynamics, etc, not in-house developed systems) implementation at the case company and should have at least 10 years of ERP systems experience in UK. The integrative KM competence framework has been tested in the service industry. Table 1 illustrates the background of the ERP implementation of three companies (X, Y and $\mathrm{Z}$ ) ranging from small, medium and large size.

Table 1. Background of the companies of small, medium and large size

\begin{tabular}{|l|l|l|l|l|l|}
\hline Company & Business area & $\begin{array}{l}\text { ERP } \\
\text { package }\end{array}$ & $\begin{array}{l}\text { Number of } \\
\text { modules }\end{array}$ & $\begin{array}{l}\text { Implementation } \\
\text { duration }\end{array}$ & $\begin{array}{l}\text { Number of } \\
\text { employees/ active } \\
\text { ERP users }\end{array}$ \\
\hline Company X & Music & Oracle & 18 modules & 3.5 years & $160 / 120$ \\
\hline Company Y & Market Research & Oracle & 10 modules & 1.5 years & $1500 / 1500$ \\
\hline Company Z & Broadcasting & Oracle & 12 modules & 1.5 years & $5000 / 5000$ \\
\hline
\end{tabular}

Even the size of the three companies are different, all of them have implemented the same ERP package (Oracle), there have not been any package specific features affect the findings of the study. Almost all employees are using the system which shows that enterprise wide decision making requirements have been satisfied by the ERP system itself. The implementation duration mainly depends on the number of modules and customisation efforts in order to facilitate specific business requirements in each business area. Each interview participant had direct work experience on ERP implementations for more than 15 years which shows the high level of skills and experience in ERP domain. They all have ERP implementation experience in UK including the direct involvement of the respective implementation. Each company implementation has been investigated with three different sources of evidence: 6 hours of in-depth interviews in total, analysis of ERP project related documents, and validation of coded data with the respective companies. Moreover, an interview template has been developed in order to validate the links between the components and thereby find out the applicability of the IKMC framework in practice. The interview mainly comprised 4 groups of questions with regard to ERP package knowledge, business process knowledge, organisational cultural knowledge and project management knowledge. Semi-structured interviews were carried out with ERP experts in respective companies. The purpose of the research and the structure of the interview were briefed to the participants before commencing the interview session. 


\subsection{Data Analysis and Findings}

In this section, four propositions have been formulated in order to assess the degree to which knowledge management competence influences ERP implementation success with respect to the k-types, k-layers and KM life cycle phases which can be seen in the integrative framework. Word for word interview transcripts and ERP project documents were analysed using thematic, comparative and content analysis methods [40-42]. The thematic analysis was used to allow new themes to emerge from the transcripts and documents, whilst comparative and content analysis methods have been used to confirm the set of themes those were there before commencing the coding [41, 42], themes such as what, how and why different types of knowledge have been created, transferred, retained and applied during implementation. Furthermore, comparative analysis was used to confirm findings across 3 companies. The data analysis process is comprised of 3 steps: it identifies what, how, why and with-what the knowledge is created, transferred, retained and applied in step 1. In step 2 , it categorises all knowledge activities under main four knowledge types. In step 3, it derives the key findings based on the frequent of occurrence of knowledge activities in 3 implementations. The k-layers (what, how, why, with) have been used to reveal the importance of four k-types in different KM life cycle phases and thereby produced the research findings with the integrated effects of k-layers, k-types and KM life cycle phases. The four propositions are discussed with evidence from the case companies based on 3 implementations which have been carried out in company X, company $\mathrm{Y}$ and company Z.

Proposition 1: The management of ERP package knowledge with the support of KM life cycle phases to achieve ERP success.

Proposition 2: The management of business process knowledge with the support of KM life cycle phases to achieve ERP success.

Proposition 3: The management of organisational cultural knowledge with the support of KM life cycle phases to achieve ERP success.

Proposition 4: The management of project management knowledge with the support of KM life cycle phases to achieve ERP success.

The summary of key findings can be seen in Table 2; it shows that ERP package and business process knowledge have been managed formally through the KM life cycle phases, but there is not much evidence of managing organisational cultural and project management knowledge formally through KM life cycle phases. 
Table 2. Summary of key findings

\begin{tabular}{|c|c|c|c|c|}
\hline \multirow{2}{*}{\begin{tabular}{|c|}
\multicolumn{1}{|c|}{ K-type } \\
\multicolumn{1}{c}{ ERP } \\
package \\
Knowledge
\end{tabular}} & \multicolumn{4}{|c|}{ KM life cycle phases: } \\
\hline & K-creation & K-transfer & K-retention & $\begin{array}{c}\text { K- } \\
\text { application }\end{array}$ \\
\hline \begin{tabular}{l}
\multicolumn{1}{c}{ ERP } \\
package \\
Knowledge
\end{tabular} & $\begin{array}{l}\text { Client and vendor } \\
\text { project teams should } \\
\text { be in one physical } \\
\text { location (on-shore) to } \\
\text { experience smooth } \\
\text { knowledge creation } \\
\text { between individuals. }\end{array}$ & \begin{tabular}{lr}
\multicolumn{1}{c}{ Main } & ERP \\
package & related \\
knowledge & transfer \\
methods & are \\
workshops, training \\
sessions, piloting the \\
system and UAT \\
(user acceptance \\
test).
\end{tabular} & $\begin{array}{l}\text { There are few } \\
\text { ways of retaining } \\
\text { ERP package } \\
\text { related knowledge } \\
\text { such as } \\
\text { documentation, as } \\
\text { help desk activities, } \\
\text { handovers and } \\
\text { buddy systems. }\end{array}$ & $\begin{array}{l}\quad \text { Quality of } \\
\text { documentation } \\
\text { determines the } \\
\text { knowledge } \\
\text { application } \\
\text { during the } \\
\text { implementation. }\end{array}$ \\
\hline & \begin{tabular}{l}
\multicolumn{1}{c}{ Online $\mathrm{KM}$} \\
systems managed by \\
vendors determines \\
the ERP package \\
knowledge creation \\
mainly in the latter \\
stage of the \\
implementation.
\end{tabular} & $\begin{array}{l}\text { Use of train the } \\
\text { trainer } \\
\text { during approach } \\
\text { implementations. }\end{array}$ & $\begin{array}{l}\text { Documentation } \\
\text { or practice of } \\
\text { document } \\
\text { management is the } \\
\text { commonly used } \\
\text { method. }\end{array}$ & \\
\hline & $\begin{array}{l}\text { Informal } \\
\text { conversations also } \\
\text { support ror } \\
\text { knowledge creation } \\
\text { along with formal } \\
\text { project meetings and } \\
\text { brainstorming } \\
\text { sessions. }\end{array}$ & $\begin{array}{l}\text { The organisation } \\
\text { structure sees as a } \\
\text { determinant for k- } \\
\text { transfer during ERP } \\
\text { implementation. }\end{array}$ & & \\
\hline \begin{tabular}{l}
\multicolumn{1}{c}{ Business } \\
process \\
Knowledge
\end{tabular} & $\begin{array}{l}\text { Business process } \\
\text { related knowledge } \\
\text { has been created } \\
\text { mainly through the } \\
\text { super users. }\end{array}$ & $\begin{array}{l}\quad \text { The super users } \\
\text { mainly take the lead } \\
\text { to transfer current } \\
\text { business process } \\
\text { knowledge to } \\
\text { consultants with the } \\
\text { support of other } \\
\text { users. }\end{array}$ & \begin{tabular}{lr}
\multicolumn{1}{c}{ The } & main \\
approach & of \\
retaining & business \\
process related \\
knowledge & is with \\
As Is Is process \\
documents.
\end{tabular} & $\begin{array}{l}\quad \text { The As Is } \\
\text { process } \\
\text { documents } \\
\text { mainly use to } \\
\text { plan data } \\
\text { migrations and } \\
\text { in } \\
\text { customisations. }\end{array}$ \\
\hline & $\begin{array}{l}\text { It is vital to know } \\
\text { the As Is process in } \\
\text { order to determine } \\
\text { the To Be process. }\end{array}$ & $\begin{array}{l}\text { Effective } \\
\text { knowledge transfer is } \\
\text { determined by the } \\
\text { knowledge } \\
\text { absorption capability } \\
\text { of the } \\
\text { consultant/user. }\end{array}$ & $\begin{array}{l}\text { Higher the } \\
\text { customisations, } \\
\text { higher the time and } \\
\text { effort put to prepare } \\
\text { As Is documents to } \\
\text { a greater detail. }\end{array}$ & \\
\hline $\begin{array}{c}\text { Org. } \\
\text { Cultural }\end{array}$ & $\begin{array}{l}\text { A consultant's previ } \\
\text { to identify and adapt to }\end{array}$ & $\begin{array}{l}\text { us implementation exp } \\
\text { he culture of the client }\end{array}$ & $\begin{array}{l}\text { ence in a similar in } \\
\text { ranisation. }\end{array}$ & stry matters a lot \\
\hline Knowledge & $\begin{array}{l}\text { There have been diff } \\
\text { requirement gathering }\end{array}$ & $\begin{array}{l}\text { iculties in taking process } \\
\text { liscussions. }\end{array}$ & nformation out of use & rs during business \\
\hline & $\begin{array}{l}\text { Companies deal wit } \\
\text { attempting to retain tha }\end{array}$ & $\begin{array}{l}\mathrm{h} \text { organisation cultural } \\
\text { knowledge, since it is d }\end{array}$ & $\begin{array}{l}\text { elated activities then } \\
\text { fficult to codify that } \mathrm{kr}\end{array}$ & $\begin{array}{l}\text { and there without } \\
\text { lowledge. }\end{array}$ \\
\hline $\begin{array}{c}\text { Project } \\
\text { Management }\end{array}$ & $\begin{array}{l}\text { ERP implementatior } \\
\text { only the facilitation. }\end{array}$ & is are run by the vendor & itself and client's proj & ect manager does \\
\hline Knowledge & $\begin{array}{l}\text { Project managers } \\
\text { knowledge. }\end{array}$ & ppointed by the clien & companies are wit & h no prior ERP \\
\hline & $\begin{array}{r}\text { It is pointless to } \mathrm{c} \\
\text { up that knowledge at }\end{array}$ & $\begin{array}{l}\text { and retain the proje } \\
\text { pertise within the cl }\end{array}$ & $\begin{array}{l}\text { anagement know } \\
\text { company. }\end{array}$ & in order to build \\
\hline
\end{tabular}


Proposition 1: The management of ERP package knowledge with the support of KM life cycle phases to achieve ERP success.

\section{Knowledge creation phase}

The individual and organisational knowledge about a new ERP system starts from zero and it grows with the implementation. Regardless of a vanilla implementation or replacement, active participation of consultants is vital for ERP package related knowledge creation [20]. Therefore, client and vendor project teams should be together in one particular physical location in order to experience a smooth knowledge creation between individuals during an implementation. Furthermore, client and vendor teams should be merged together in such a way that one consultant works with one super user depending on the stage of the implementation. The offshore (client and vendor project teams work remotely) work method has not materialised expected knowledge creation. However, depending on the individual consultant's attitude and positive or negative work relationship with the client project team members, some tend to share most of the knowledge with the client, but some not. The online KM systems managed by vendors determines the creation of ERP package knowledge not necessarily in the beginning but towards the latter stage of the implementation. Oracle has their own online knowledge base called Metalink (My Oracle Support), which comprises thousands of knowledge elements pertaining to Oracle ERP. Moreover, ERP package related knowledge such as functions and features of the system has been created during formal project meetings and brainstorming sessions [43]. The knowledge creation has happened during many informal chats, for an instance project related issues being discussed in corridors and social occasions. At that time the discussion mostly shifts to a different level. So users tend to discuss an issue in detail, which they could not do during the meeting because of shyness or unwillingness to go against the boss, or any other reason. But they might be more open when it comes to informal chats, although it would be very difficult to codify that knowledge in full [16]. However, as a result, a summary of the issue that has been discussed in the corridor or social occasion might go to formal records if it is worked out.

\section{Knowledge transfer phase}

The main ERP package related knowledge transfer methods are workshops, training sessions, piloting the system and UAT (user acceptance test) according to findings. When the UAT stage comes many users have forgotten what they have learnt during training sessions, because they are normally busy with day to day office work. So, they learn a great deal about the ERP system during UAT because users should provide sign offs for UAT scripts. It forces them to grab the knowledge of the system willingly or unwillingly. Therefore, UAT becomes a determinant for k-transfer as far as ERP package knowledge is concerned. Furthermore, training sessions can be conducted internally for all users of the system, mostly conducted during the implementation by the vendor and also the client organisation can send selected users or super users for external intensive training to the vendor. Many companies use a train the trainer approach in educating other users who could not attend training sessions. This shows how, why and with what ERP package knowledge has been 
transferred at respective stages of the implementation. In addition, project team members should be selected correctly for the implementation from the client company [5]. They are called key or super users. They have detailed knowledge of the business processes and will be appointed by the respective departments/functions. Super users should be responsible of facilitating smooth knowledge transfer between consultants to end users and vice versa [20]. Moreover, organisation structure is seen as a determinant for k-transfer during ERP implementation. The client company should compare the existing organisational structure with the To Be structure after the system implementation, thereby identifying the roles and responsibilities of the employees and start transferring adequate knowledge to the correct employee from the beginning.

\section{Knowledge retention phase}

There are few ways of retaining ERP package related knowledge such as documentation, help desk activities, handovers and buddy systems. Documentation or practice of document management is the most commonly used method [44]. Documents are in a few types such as process documents, setup documents, technical documents and training manuals. The case companies mainly used a shared drive on the network to store documents for re-use during the implementation. Documents were updated frequently, versioned and given access for relevant users. If there are many customisations, the company should retain existing employees who were there during the implementation, because they are the only people who know about the changes did to the standard system in detail in order to operate and maintain the system. Moreover, clients tend to maintain documents according to vendor's document configuration methods. For instance Oracle consultants use AIM (application implementation methodology) as implementation methodology and it contains a way of configuring implementation related documents with specific formats.

\section{Knowledge application phase}

It is important to pick the knowledge at the beginning and pass it all through the ERP implementation cycle. The solution design documents have been used during the UAT stage and interface development stage, this implies that clients require the knowledge that they created, transferred and retained at the beginning of the implementation in order to accomplish tasks in middle and latter stages of the implementation. Hence, the quality of documentation determines the application of relevant knowledge during implementation. Documents produced during the implementation should be accurate and up-to-date; otherwise usage of the same will lead the implementation to failure.

The ERP package knowledge helps users to move from data entry person to analytical person. As the awareness and knowledge about the ERP system increases, integrated and accurate information can be pulled from various types of reports and screens to make effective management decisions. Thereby, it improves organisational results and capabilities by reducing costs and maximising profits. In summary, ERP package related knowledge would increase the KM competence and it is fundamental and very important for ERP implementation success as far as four success measures are concerned. 
Proposition 2: The management of business process knowledge with the support of KM life cycle phases to achieve ERP success.

\section{Knowledge creation phase}

The business process related knowledge refers to As Is or existing process related activities in an ERP implementation [22]. It is important to identify and draw the current business process in order to determine the To Be process or how it looks like after the implementation. Most business process related knowledge is created by users and then shared among the consultants to learn and understand the business of the client company.

\section{Knowledge transfer phase}

The super users mainly take the leadership to transfer current business process knowledge to consultants with the support of other users. Thereby, consultants understand the existing way of carrying out the business activities and start mapping these into ERP system features and functions [20]. Furthermore, super users mainly take the responsibility of generating the As Is process document and publish them back to the company in order to understand users and senior executives how the whole business is operating. In between above process, there are several feedback sessions with users to validate and check the accuracy of the As Is. Moreover, the receiver of knowledge that could be either a user or a consultant should have the capability of absorbing knowledge in the right quantities. Hence, knowledge absorption capacity would determine the effective knowledge transfer between individuals during the implementation [5]. On the other hand, knowledge should be transferred to the right person, at the right time and in correct quantity by the consultant and user. It can be evidently seen that how k-layers (i.e. why, how, what and with) integrate with business process knowledge in order to transfer knowledge during implementation.

\section{Knowledge retention phase}

The main approach of retaining business process related knowledge is with As Is process documents according to the findings. These documents can be split down by the departments and/or key process areas. The As Is documents are generated at a high level without going into much detail, when there are less customisations on the ERP system to meet business requirements. If the organisation is flexible enough to adopt the standard ERP functionalities by changing the existing business processes, then there is a high probability of implementing best business practices through the new implementation. Companies published the approved As Is documents on the shared drive like other project documents, so that users can access them and see that how particular individual's work relates to others tasks of the organisation.

\section{Knowledge application phase}

The As Is process documents are mainly used to plan data migrations and in customisations. They have also been useful during UAT stage and go-live, so that users could go back and see how they used to work before the new system was 
introduced and accordingly understand the system's way of performing tasks within their respective roles when providing sign-offs for UAT scripts. The findings shows that higher the customisations, higher the time and effort put to prepare As Is documents, because it requires knowledge of the current processes to a greater detail in order to plan and develop customisations.

The system quality is mainly depended on the way in which the system is configured by understanding existing business processes. Thereby, the system is enabled to capture relevant data for management decision making in various functional areas of the organisation. Also, proper understanding of As Is process is vital to retrieve accurate and integrated information which are produced in system generated reports and on various screens of the system. In conclusion, business process knowledge is necessary and it increases the KM competence of the organisation in collaboration with k-layers and $\mathrm{KM}$ life cycle phases to achieve ERP success.

Proposition 3: The management of organisational cultural knowledge with the support of KM life cycle phases to achieve ERP success.

A consultant's previous implementation experience in a similar industry matters a lot to identify and adapt to the culture of the client organisation. Moreover, there would be difficulties in taking information out of users during business requirement gathering discussions for various reasons such as fear of losing knowledge and power, resistance to the new system, etc, so it implies that project team should fight with own internal culture $[33,45]$. On the other hand, battles between business and technical staff such as finalising customisation points and requirements are common during an implementation. Senior executives' interference in these situations is vital to direct them on correct path.

The impact from the organisation culture depends on how long the existing systems have been in place. Whatever system is implemented, at the end of the day it will be used by an individual with a set of attitudes towards the system and bound by the culture of the organisation [45]. Therefore, it is vital to pay attention to the culture the business operates in. However, organisational cultural knowledge resides in individual's minds and has not been codified through KM life cycle phases during ERP implementations. Companies deal with organisation cultural related activities then and there without attempting to retain that knowledge, since it is difficult to codify that knowledge. However, it can be seen that how and why (k-layers) organisational cultural knowledge is important to achieve ERP implementation success.

Proposition 4: The management of project management knowledge with the support of KM life cycle phases to achieve ERP success.

The project management knowledge creation, transfer, retention and application occur informally most of the time during an implementation. The case companies were left with project plans, estimations and charts end of the implementation. Apart from that there has not been any codification of knowledge through KM life cycle phases [16]. Many of the implementations are run by the vendor itself and client's project manager does only the facilitation. Most of the project managers appointed by the client companies have no prior ERP knowledge. Therefore, clients heavily rely on the vendor for project management related activities [5]. Some believe that the 
fundamentals of a software project are the same; there will only be slight differences in estimations, resource requirements, etc. Even though they formally retain project management knowledge that would not be at least useful for ERP system upgrades according to the case companies.

The companies ranked the importance of knowledge types which would increase KM competence for ERP implementation success as shown in Table 3. Rank 1 to 4 from very important to least important.

Table 3. Ranking of knowledge types

\begin{tabular}{|l|l|l|l|}
\hline Company & X & Y & Z \\
\cline { 1 - 4 } K-type & & 1 & 1 \\
\hline ERP package K & 1 & 2 & 1 \\
\hline Business process K & 2 & 4 & 4 \\
\hline Org. Cultural K & 2 & 3 & 3 \\
\hline Project Mgmt K & 4 & & \\
\hline
\end{tabular}

This implies that ERP package knowledge is the most important k-type and secondly business process knowledge. The organisational cultural and project management knowledge types are less important than other two. It reflects that in practice they perform formal knowledge creation, transfer, retention and application only as far as ERP package and business process k-types are concerned, but not with organisational cultural and project management knowledge types.

\section{Discussion}

Out of the four k-types, ERP package knowledge and business process knowledge have been extensively used and are relevant to industrial practices. The organisational cultural and project management knowledge have been less used in actual ERP implementations in order to increase KM competence of the organisation. This shows that research outcomes are partially in line with Alavi and Leidner [22] as far as ktypes are concerned. Nevertheless, the four k-layers have shown the applicability to reveal the KM competence with the support of k-types and KM life cycle phases to achieve ERP success in service industry. K-layers were used by Chen [23] for IT industry in his study and through this research k-layers were used specifically to ERP context integrated with k-types and KM life cycle phases.

The four ERP success measures (system quality, information quality, individual impact and organisational impact) have been used to enable effective decision making in various functional areas of the organisation such as finance, marketing, human resource, operations and sales. Higher the level of As Is process knowledge and ERP package knowledge, higher the system quality and quality of the information that the system produces in reports and on screen for decision making. Therefore, individual capabilities and effectiveness on operational and managerial decision making have been improved through the new system implementation. Eventually, organisational results have also been increased in three business areas due to effective decision making of the employees through the ERP system. 
The research reveals the integration of the three components i.e. k-types, k-layers and KM life cycle to build up KM competence within the organisation to achieve ultimate ERP implementation success, thereby, improving the decision making performance in various functional areas of the organisation. Moreover, this research shows the applicability of the IKMC framework in industrial real situations, which provides an integrative perspective on KM for the ERP implementation domain.

\section{Conclusion}

The research is important for industrial practitioners and academics in three main ways. Firstly it classifies key findings on knowledge creation, transfer, retention and application with respect to $\mathrm{KM}$ competence through the integrative framework. Therefore, practitioners can emphasise those key findings during ERP implementations. Secondly, it informs practitioners about the most important knowledge types (ERP package and business process knowledge) and how, why and with what to create, transfer, retain and re-use knowledge during an ERP implementation to achieve project success. Furthermore, they can prioritise and provide less attention on less important k-types. Thirdly, this is the first integrative framework that discovers what, how, why and with ERP package, business process, organisational cultural and project management knowledge have been created, transferred, retained and applied during ERP implementations. Thereby, this study adds new academic knowledge to KM and ERP domain. If implemented properly by considering these KM aspects, the ERP system should act as an integrated decision making system at all levels of the organisation.

Nevertheless, this research has some limitations; it focuses only on implementation, not pre or post implementation. Furthermore, the sample only covers Oracle ERP product implementations in UK service industry.

Further research will extend the IKMC framework to cover more standard ERP products in other regions apart from UK and extend the investigation to other industries such as manufacturing. Moreover, a quantitative survey will be carried out to find out the importance of k-types to increase KM competence with the links of klayers and KM life cycle. Therefore, the applicability and validity of the framework can be generalised for more industrial contexts. Finally, the integrative framework will be extended for the pre and post implementation stages as well.

\section{References}

1. Davenport, T.H.: Putting the enterprise into the enterprise system. Harvard Business Review, 121-131 (July-August 1998)

2. Li, H., Li, L.: Integrating systems concepts into manufacturing information systems. Systems Research and Behavioral Science 17, 135-147 (2000)

3. O'Leary, D.E.: Enterprise Resource Planning System: Systems, Lifecycle, Electronic Commerce and Risk. Cambridge University Press, Cambridge (2000)

4. Kumar, K., van Hillegersberg, J.: Enterprise resource planning experiences and evolution. Communications of the ACM 43, 22-26 (2000)

5. Jones, M.C., Cline, M., Ryan, S.: Exploring knowledge sharing in ERP implementation, an organizational culture framework. Decision Support Systems 41, 411-434 (2006) 
6. Kraemmerand, P., Møller, C., Boer, H.: ERP implementation: An integrated process of radical change and continuous learning. Production Planning \& Control 14, 338-348 (2003)

7. Murray, P.: Knowledge management as a sustained competitive advantage. Ivey Business Journal 66, 71-76 (2002)

8. Poston, R., Grabski, S.: Financial impacts of enterprise resource planning implementations. International Journal of Accounting Information Systems, 271-294 (December 2001)

9. Nah, F., Lau, J., Kuang, J.: Critical factors for successful implementation of enterprise systems. Business Process Management Journal 7, 285-296 (2001)

10. Somers, T.M., Nelson, K.: The Impact of Critical Success Factors across the Stages of Enterprise Resource Planning Implementations. In: Proceedings of the 34th Hawaii International Conference on System Sciences (HICSS) (Year)

11. Huang, S., Chang, I., Li, S., Lin, M.: Assessing risk in ERP projects: identify and prioritize the factors. Industrial Management \& Data Systems 104, 681-688 (2004)

12. Wong, A., Scarbrough, H., Chau, P., Davison, R.: Critical Failure Factors in ERP Implementation. In: Proceedings of the Ninth Pacific Asia Conference on Information Systems (PACIS) (Year)

13. Upadhyay, P., Jahanyan, S., Dan, P.: Factors influencing ERP implementation in Indian manufacturing organizations. Journal of Enterprise Information Management 24, 130-145 (2011)

14. Al-Turki, U.M.: An exploratory study of ERP implementation in Saudi Arabia. Production Planning \& Control 22, 403-413 (2011)

15. Dey, P.K., Clegg, B., Cheffi, W.: Risk management in enterprise resource planning implementation: a new risk assessment framework. Production Planning \& Control, 1-14 (2011)

16. Vandaie, R.: The role of organizational knowledge management in successful ERP implementation projects. Knowledge-Based Systems 21, 920-926 (2008)

17. Sedera, D., Gable, G.: Knowledge management competence for enterprise system success. Journal of Strategic Information Systems 19, 296-306 (2010)

18. Sedera, D., Gable, G., Chan, T.: Knowledge management for ERP success. In: Pacific Asia Conference on Information Systems (2003)

19. Gable, G.G., Sedera, D., Chan, T.: Re-conceptualizing Information System Success: The IS-Impact Measurement Model. Journal of the Association for Information Systems 9, 377-408 (2008)

20. Maditinos, D., Chatzoudes, D., Tsairidis, C.: Factors affecting ERP system implementation effectiveness. Journal of Enterprise Information Management 25, 60-78 (2012)

21. O'Leary, D.E.: Knowledge management across the enterprise resource planning systems life cycle. International Journal of Accounting Information Systems 3, 99-110 (2002)

22. Alavi, M., Leidner, D.: Review: knowledge management and knowledge management systems: conceptual foundations and research issues. MIS Quarterly (MISQ Review) 25, 107-136 (2001)

23. Chen, Y.-J.: Development of a method for ontology-based empirical knowledge representation and reasoning. Decision Support Systems 50, 1-20 (2010)

24. Liu, S., Annansingh, F., Moizer, J., Liu, L., Sun, W.: A knowledge system for integrated production waste elimination in support of organisational decision making. In: Hernández, J.E., Zarate, P., Dargam, F., Delibašić, B., Liu, S., Ribeiro, R. (eds.) EWG-DSS 2011. LNBIP, vol. 121, pp. 134-150. Springer, Heidelberg (2012) 
25. Gable, G.: The enterprise system lifecycle: through a knowledge management lens. Strategic Change 14, 255-263 (2005)

26. Huber, G.P.: Organizational Learning: The Contributing Processes and the Literatures. Organization Science 2, 88-115 (1991)

27. Stein, E.W., Zwass, V.: Actualizing Organizational Memory with Information Systems. Information Systems Research 6, 85-117 (1995)

28. Szulanski, G.: Exploring Internal Stickness: Impediments to the Transfer of Best Practice within the Firm. Strategic Management Journal 17, 27-43 (1996)

29. Bartezzaghi, E., Corso, M., Verganti, R.: Continuous Improvement and Inter-Project Learning in New Product Development. International Journal of Technology Management 14, 116-138 (1997)

30. Wiig, K.M.: Knowledge Management: Where Did it Come From and Where will it Go. Journal of Expert Systems with Applications 13, 1-14 (1997)

31. Argote, L.: Organizational Learning: Creating, Retaining and Transferring Knowledge. Kluwer Academic Publishers, Boston (1999)

32. Horwitch, M., Armacost, R.: Helping Knowledge Management Be all it Can Be. Journal of Business Strategy 23, 26-31 (2002)

33. Hung, W.-H., Ho, C.-F., Jou, J.-J., Kung, K.-H.: Relationship bonding for a better knowledge transfer climate: An ERP implementation research. Decision Support Systems 52, 406-414 (2012)

34. Liu, S., Leat, M., Moizer, J., Megicks, P., Kasturiratne, D.: A decision-focused knowledge management framework to support collaborative decision making for lean supply chain management. International Journal of Production Research, 1-15 (2012)

35. Carton, F., Adam, F.: Understanding the Impact of Enterprise Systems on Management Decision Making: An Agenda for Future Research. The Electronic Journal of Information Systems Evaluation 8, 99-106 (2005)

36. Sammon, D., Adam, F., Carton, F.: The Realities of Benefit Realisation in the Monolithic Enterprise Systems Era- Considerations for the Future. In: Proceedings of the 10th European Conference on Information Technology Evaluation (Year)

37. Baskerville, R., Pawlowski, S., McLean, E.: Enterprise resource planning and organizational knowledge: patterns of convergence and divergence. In: International Conference on Information Systems (Year)

38. McAdam, R., Galloway, A.: Enterprise resource planning and organisational innovation: a management perspective. Industrial Management \& Data Systems 105, 280-290 (2005)

39. Newell, S., Huang, J.C., Galliers, R.D., Pan, S.L.: Implementing enterprise resource planning and knowledge management systems in tandem, fostering efficiency and innovation complementarity. Information \& Organisation 13, 25-52 (2003)

40. Miles, M.B., Huberman, A.M.: An Expanded Sourcebook Qualitative Data Analysis. Sage Publications, California (1994)

41. Dawson, C.: Practical Research Methods. How to Books, Oxford (2002)

42. Tharenou, P., Donohue, R., Cooper, B.: Management Research Methods. Cambridge University Press, New York (2007)

43. Xu, L., Wang, C., Luo, X., Shi, Z.: Integrating knowledge management and ERP in enterprise information systems. Systems Research and Behavioral Science 23, 147-156 (2006)

44. Tsai, M.-T., Li, E.Y., Lee, K.-W., Tung, W.-H.: Beyond ERP implementation: the moderating effect of knowledge management on business performance. Total Quality Management \& Business Excellence 22, 131-144 (2011)

45. Donate, M.J., Guadamillas, F.: Organizational factors to support knowledge management and innovation. Journal of Knowledge Management 15, 890-914 (2011) 